\title{
Toward a Universal Account of Country-induced Predispositions Integrative Framework and Measurement of Country-of-origin Images and Country Emotions
}

\author{
Kock, Florian; Josiassen, Alexander; Assaf, A. George
}

Document Version

Accepted author manuscript

Published in:

Journal of International Marketing

DOI:

$10.1177 / 1069031 \times 19857692$

Publication date:

2019

License

Unspecified

Citation for published version (APA):

Kock, F., Josiassen, A., \& Assaf, A. G. (2019). Toward a Universal Account of Country-induced Predispositions: Integrative Framework and Measurement of Country-of-origin Images and Country Emotions. Journal of International Marketing, 27(3), 43-59. https://doi.org/10.1177/1069031X19857692

Link to publication in CBS Research Portal

\section{General rights}

Copyright and moral rights for the publications made accessible in the public portal are retained by the authors and/or other copyright owners and it is a condition of accessing publications that users recognise and abide by the legal requirements associated with these rights.

\section{Take down policy}

If you believe that this document breaches copyright please contact us (research.lib@cbs.dk) providing details, and we will remove access to the work immediately and investigate your claim. 


\section{Toward a Universal Account of Country-induced Predispositions: Integrative Framework and Measurement of Country-of-origin Images and Country Emotions} Florian Kock, Alexander Josiassen, and A. George Assaf

Journal article (Accepted manuscript*)

\section{Please cite this article as:}

Kock, F., Josiassen, A., \& Assaf, A. G. (2019). Toward a Universal Account of Country-induced Predispositions: Integrative Framework and Measurement of Country-of-origin Images and Country Emotions. Journal of International Marketing, 27(3), 43-59. https://doi.org/10.1177/1069031K19857692

\section{DOl: https://doi.org/10.1177/1069031X19857692}

Copyright (C) The Author(s) २०19. Reprinted by permission of SAGE Publications.

* This version of the article has been accepted for publication and undergone full peer review but has not been through the copyediting, typesetting, pagination and proofreading process, which may lead to differences between this version and the publisher's final version AKA Version of Record. 
Final version published as:

Kock, F., Josiassen, A., and Assaf, A. G. (2019). Toward a universal account of countryinduced predispositions: integrative framework and measurement of country-of-origin images and country emotions. Journal of International Marketing, 27(3), 43-59.

\title{
Toward a universal account of country-induced predispositions:
}

\section{Integrative framework and measurement of country of origin images}

\section{and country emotions}

\begin{abstract}
Understanding how consumers use the country of origin cue of a product is fundamental to explain their behavior in a globalized marketplace. While the study of country of origin is one of the most popular topics in international marketing, the ongoing ambiguity regarding its conceptualization, composite nature, operationalization and measurement deserves further scrutiny. The authors propose an integrative framework which unites two separate areas of research on the country of origin cue: Performance-related country of origin images and performance-unrelated country emotions. The authors reconcile diverse existing perspectives from both areas into the overarching country-induced predispositions (CIP) model. Conceptualizations and measurement approaches for the model's five components are developed and empirically validated across three countries and with five countries of origin. The model offers researchers and managers with an interest in the country of origin cue a flexible and operational roadmap, with scales both for in-depth analyses and parsimonious additional testing.
\end{abstract}


Keywords: country of origin image, country emotions, country-induced predispositions (CIP), animosity, affinity, attitude.

\section{INTRODCUTION}

In today's globalized markets, consumers are exposed to a wide variety of products and services from across the world. Facing a broad range of options while having limited product knowledge, consumers are likely to rely on the country of origin cue to inform their purchase decisions. Accordingly, nearly $75 \%$ of global consumers list the country of origin as a key purchase driver (Nielsen 2016). Academia supports this observation, providing comprehensive documentation of the effect of the country of origin cue on consumers' product preference (e.g. Herz and Diamantopoulos 2017; Maheswaran 1994; Verlegh, Steenkamp and Meulenberg 2005). Likewise, the study of country of origin has become one of the most popular marketing research themes with more than 1,000 publications (Samiee and Chabowski 2012). This popularity is at least in part due to its promise of being easy to understand and apply. However, its intuitive but impalpable nature is both a blessing and a curse. It is a blessing because its visceral meaning is highly attractive for both researchers and international marketing managers, resulting in a myriad of empirical and managerial applications over the recent four decades. However, it is also a curse because these applications often rest on ambiguous or conflicting assumptions and perspectives of what the country of origin cue is and how it should be measured. 
In the extant literature, consumers' attitudes toward the country of origin, which we summarize under the generic label 'country-induced predispositions' (CIP), have been defined and measured in a variety of ways. While almost all researchers agree that country of origin judgments are based on images or mental representations, and that they affect consumer behavior, no consensus exists as to the conceptual and operational nature of the country of origin cue as it exists in consumers' minds. While many of the existing research accounts are conceptually comprehensive and carefully executed, the sheer myriad of perspectives makes it almost impossible to compare extant studies and select the most adequate approach for a particular research goal.

To start with, we identify three research gaps that have contributed to this conceptual and operational ambiguity of CIP and address them in a unifying model. The first important gap is that existing studies do not agree on whether consumers' CIP are product performancerelated or also reflect emotions that go beyond mere performance-related cues. Performancerelated CIP are often referred to as 'country (of origin) image' and make up the lion's share of studies in the existing literature; this research stream investigates the country as a cognitive cue which consumers use to infer product attributes, such as quality (e.g., Koschate-Fischer, Diamantopoulos, and Oldenkotte 2012; Verlegh and Steenkamp 1999). Performanceunrelated CIP are only rarely investigated. However, emotions that consumers experience toward countries themselves also influence consumers' preferences beyond mere quality considerations (Maheswaran and Chen 2006; Maheswaran, Chen and He 2015; Papadopoulos, El Banna and Murphy 2017; Shankarmahesh 2006).

The second important gap is that those studies that examine cognitive, performancerelated CIP diverge on whether it constitutes various descriptive attributes about a particular country of origin (e.g., Durand, Turkina and Robson 2016; Martin and Eroglu 1993) or is rather stored as an evaluative condensate of the country (e.g., Kotler, Haider and Rein 1993; 
Zeugner-Roth, Žabkar and Diamantopoulos 2015). This difference is of importance as it determines the very nature of the construct as well as its measurement. Various perspectives have all too often been confounded under the generic 'country of origin' label, consequently leading many marketing researchers to conclude that the literature lacks a unifying theorybased framework that accounts for the complexities in understanding the impact of the country cue on consumer behavior (Josiassen and Harzing 2008; Maheswaran et al. 2013; Verlegh and Steenkamp 1999).

Third, while many studies highlight the importance of country-related emotions as determinants of consumer preferences, limited empirical work exists as to the nature and role of these emotions (Gürhan-Canli, Sarial-Abi and Hayran 2018), their measurement and how to integrate them into a framework with cognitive, performance-related CIP. As a consequence of this gap, we know very little about the potential interaction between performance-related cognitions and performance-unrelated emotions in driving consumers' product preferences.

Against this background, we outline three key research aims to address these gaps, culminating in the development and empirical validation of the CIP model. The first research aim is to review accounts of country of origin research and identify two distinct, yet complementary research streams: cognitive, performance-related country of origin images and performance-unrelated country emotions. The second research aim is to, by drawing on this distinction, develop a conceptual sub-model and its components for each of these two research streams, and then synthesize them into a unifying framework, the CIP model. The CIP model explains how consumers mentally store information about and respond to the country of origin cue, both through a performance-related and performance-unrelated pathway. The first sub-model, which we refer to as the imagery-image model, focuses on performance-related country images, and conceptualizes and delineates two constructs: 
Imagery is a multidimensional concept consisting of diverse cognitive associations and image is a unidimensional summary evaluation thereof. The second sub-model focuses on performance-unrelated country emotions and conceptualizes dimensions of positive and negative emotions that consumers may experience toward countries, thereby accounting for the complexities of country-related affect. Specifically, we develop and test multidimensional affinity and animosity constructs, as well as a holistic country affect component. In each submodel, constructs are integrated in a bottom-up framework in which the multiple associations and emotions inform the holistic evaluation.

The third research aim is to provide a blueprint for measuring each of the components in the CIP model, to validate them empirically across two studies with more than 1500 U.S. respondents, and to better understand how the country of origin cue informs consumer behavior. Drawing on methodological insights from cognitive and social psychology, as well as marketing, this blueprint takes into account operational ambiguities of existing approaches to the measurement of 'country of origin image' and develops new and parsimonious measures. For example, we apply a qualitative-quantitative perceptual mapping approach to measure consumers' imagery of a country of origin, and use an emoticon approach for measuring holistic country affect.

Our CIP model conciliates and unifies existing, often conflicting views in country of origin research. For researchers interested in studying the country of origin cue, our study provides rich guidance for how to conceptually and methodologically approach this important but complex marketing topic. Specifically, we develop and empirically validate five components of the country of origin cue that allow researchers to study this important but complex phenomenon at various levels of detail. We thereby address the insightful notion of Maheswaran et al. (2015, p. 165) that "the diversity and complexity of effects also strongly underscores the need for an integrated framework to systematically examine both the 
performance-related and the emotion-related country of origin effects." For managers, the multi-component CIP model provides an easy to use yet powerful tool to examine how consumers use the country of origin cue in their purchase behavior. A manager can use the CIP framework to understand the equity of a respective country of origin along five different, yet related components. Through this enriched understanding of what consumers actually know and how they feel about a specific country of origin, managers gain new insight into how to actively use the country of origin cue as an important marketing instrument in today's globalized marketplaces. Further, our framework also provides a rare account of how to examine the interaction between performance-related cognitions and performance-unrelated country emotions in consumers' minds, thereby addressing recent calls for research on the role of emotions toward local and global brands (Gürhan-Canli et al. 2018).

\section{CONCEPTUAL BACKGROUND AND MODEL DEVELOPMENT}

The country of origin cue influences consumers' preferences through two pathways (Figure 1): performance-related cognitions and performance-unrelated emotions. Understanding the difference between these two types of consumers' CIP is central for the development of an encompassing and inclusive conceptualization thereof. Existing research has yet to comprehensively examine this distinction and empirical investigations thereof are remarkably scarce, which has motivated researchers to call for conceptual and empirical advancement in country of origin research (Josiassen 2011; Maheswaran et al. 2015). On the one hand, consumers use the country cue to infer quality and expected outcomes of a product purchase (e.g. Hong and Kang 2006; Maheswaran 1994), thus, consumers mentally process the country cue to derive performance-related information about the product (Maheswaran et al. 2015). The more positive a consumer's country image, the more favorable are product 
judgements and purchase intentions toward products associated with that country (Verlegh et al. 2005). The lion's share of existing country of origin studies is devoted to this performancerelated country image perspective. Those studies (e.g., Roth and Diamantopoulos 2009; Parameswaran and Pisharodi 1994; Verlegh 2001) seek to understand the nature, conceptualization and measurement of country of origin image as a mental representation formed and held by consumers. A plethora of definitions has been suggested for the "country of origin image' concept, with little agreement on its scope and scale. Importantly, existing studies draw on at least two distinct perspectives that have often been conflated under the common 'country of origin image'. We account for these two perspectives by suggesting the constructs of country imagery and country image (Figure 1), and developing an integrative theory-based model.

On the other hand, the country of origin cue can influence consumer behavior beyond product quality perceptions (Fong, Lee and Du 2014; Josiassen 2011). As Gürhan-Canli and Maheswaran (2000a, p. 310) assert, "attitudes toward foreign products may be governed by inferences other than those about product quality." For example, Klein et al. (1998) demonstrate that while Chinese consumers evaluate Japanese products as being of high quality they still do not wish to buy them because of a feeling of animosity toward Japan. There is no inherent reason why such emotions should coincide with the performance-related country image the consumer holds about that country's products.

Emotions toward countries can stem from personal experiences, cultural, historic, military or economic country-related events and thereby exist on the country-level, not the product-level. Country-related emotions such as animosity (Klein et al. 1998) and affinity (Oberecker and Diamantopoulos 2011) are often confused with performance-related country cognitions although the two topics are distinct. Both cognitive country image and affective country emotions are crucial to understand consumers' preferences, thus, a "comprehensive 
examination of country of origin effect must include associations that are based on both product performance-related and product-unrelated aspects" (Maheswaran et al. 2013, p. 156). However, many studies have often exclusively focused on country of origin as a cognitive, performance-related cue.

Thus, we distinguish between 1) two types of CIP, 2) two types of country image content, and 3) three types of affective country emotions (Figure 1). This unifying framework allows for an organization of consumers' mental content, capturing and synthesizing the complexity of how consumers use country cues to construct their product preferences. The sound conceptualization of its components enables us to develop measures and provide an empirical investigation thereof. Moving ahead, we will first examine sub-model one, a performance-related account of cognitive country content (i.e. imagery and image), followed by sub-model two on country emotions (i.e. affinity, animosity and holistic country affect), before integrating both sub-models into the CIP model.

--- Insert Figure 1 about here ---

Various accounts in cognitive psychology research, such as Eagly and Chaiken's (1993) study of intra-attitudinal structure, provide a fertile theoretical substrate for understanding how consumers form, store and use mental representations about countries. A central tenet in attitude research is the multi-component nature of attitude, comprising cognitive and affective components, as well as an overall attitudinal component (Bodur, Brinberg and Coupey 2000). The present research follows this notion, distinguishes between these components, and structures them in a mental network that allows researchers to conceptualize and operationalize interactions between them (Eagly, Mladinic and Otto 1994).

\section{Country Imagery}


"Countries are multidimensional and complex constructs" (Chen, Mathur and Maheswaran 2014, p. 1034), and consumers are likely to store information about them as multidimensional mental content in their minds. Psychologists (e.g., Eagly and Chaiken 1993) document that a belief structure consisting of various associations linked to the psychological object underlies an individual's overall evaluation of that object. Specifically, Eagly et al. (1994) outline that the "overall evaluation of attitude objects derive from cognitions, that is, from the beliefs formed about the attitude object" (p. 113). For example, consumers' overall favorable evaluation of German cars rests on concrete beliefs such that German engineers are well-trained and diligent workers. In a similar vein, studies on country of origin suggest to conceptualize mental origin content as a host of associations that consumers link to a country as an origin of products (e.g. Durand et al. 2016; Lee, Lockshin, and Greenacre 2016; Parameswaran and Pisharodi 1994; Verlegh et al. 2005). For example, Martin and Eroglu (1993, p. 193) conceptualize a multidimensional mental representation "defined as the total of all descriptive, inferential and informational beliefs one has about a particular country." Country-related associations are cognitive descriptors that enable the individual to articulate product-related capabilities of a particular country.

A central tenet in the conceptualization of mental images is that the image is inextricably linked to an image holder. That means, the essence of an image is that it is held in individuals' minds as a subjective interpretation of reality about an object. Kotler et al. (1993, p. 141, emphasis added) state that a country image is a mental representation "that people have of a place". Against this background, this study labels the host of associations the country imagery, defined as a consumer's diverse cognitive associations relating to a country as an origin of products. This host of country of origin-related associations "may vary across products, so that it is best defined at the level of product categories" (Verlegh et al. 2005, p. 128). We add to this contention that the associations that make up imagery may also vary 
across respondents from different cultures, time (Gürhan-Canli and Maheswaran 2000a) as well as the countries of origin.

\section{Country Image}

In line with seminal attitude theory (Eagly and Chaiken 1993), we suggest that consumers store, in addition to country imagery, a summary evaluation of the country of origin in their mind that serves as an aggregated condensate of the diverse associations captured by imagery. Psychologists widely agree on defining the attitude concept as a “summary evaluation" (Ajzen 2001, p. 28) or an "overall evaluation" (Eagly et al. 1994, p. 113) of the attitude object. Drawing implicitly on the same notion, several international marketing researchers (e.g., Han 1989; Magnusson, Krishnan, Westjohn and Zdravkovic 2014) view CIP as an aggregated mental evaluation which consumers link to a specific manufacturing country. For example, Roth and Romeo (1992, p. 480) refer to "the overall perception consumers' form of products from a particular country" and Maheswaran et al. (2013, p. 160) suggest that the overall country of origin perceptions serve "as summary construct" consumers use to inform product preferences. We follow this conceptual view from attitude theory and marketing researchers, and label this overall evaluative representation of a country of origin 'country image', defined as a consumer's summary evaluation of a country as an origin of products.

An evaluation can be defined as "the imputation of some degree of goodness or badness to an entity" (Eagly and Chaiken 1993, p. 3), thus, while country imagery is multidimensional, country image is best conceptualized as a unidimensional construct that exists as an evaluative condensate of country imagery. In contrast to imagery, image contains salient mental content that does not have to be formed for every decision but can be used as a mental shortcut, thus qualifying for heuristic decision-making when motivation or ability to systematically process information is low (Chaiken 1980; Maheswaran 1994). Holding both 
imagery and an image of a country of origin enables a consumer to adequately inform decision-making under varying levels of cognitive capacity and demands.

\section{Performance-unrelated Country Emotions}

Performance-related cognitions (i.e. country imagery and country image) that consumers hold about countries have dominated country of origin research (Verlegh and Steenkamp 1999). However, psychologists and marketing researchers increasingly examine the role that affect plays in shaping attitudes, as well as judgment and decision-making (Bagozzi, Gopinath and Nyer 1999; Eagly and Chaiken 1993; Lerner, Li, Valdesolo and Kassam 2015; Pham 2004). In international marketing, researchers (Chen et al. 2014; Maheswaran and Chen 2006; Verlegh 2001; Herz and Diamantopoulos 2013) increasingly direct attention toward affective country dispositions, and their effect on consumer behavior beyond performance-related country cognitions. Importantly, studies (e.g. Hong and Kang 2006) provide evidence that consumers can hold strong positive and negative emotions toward specific countries, and even though these emotions do not directly relate to the product-performance domain, they influence consumers' predispositions toward products originating from these affect-laden countries (Josiassen 2011; Maheswaran et al. 2015).

Emotions do not only differ on arousal and valence but also vary largely on quality and function (Smith and Ellsworth 1985), thus, an inclusive account of country-related emotions needs to comprise a diverse set thereof. Existing research provides guidance on both negative and positive emotions that consumers experience toward a country for other reasons than those linked to its products. Specifically, consumers may experience anger- or fear-based emotions toward certain countries because of "remnants of antipathy related to previous or ongoing military, political, or economic events" (Klein et al. 1998, p. 90). This affective predisposition is labeled "animosity" (Harmeling, Magnusson and Singh 2015; Klein et al. 1998). Analogously, a country may also elicit feelings of affinity (Oberecker and 
Diamantopoulos 2011) among consumers, which refers to "a feeling of liking, sympathy, and even attachment toward a specific foreign country" (p. 46). Neither animosity nor affinity are performance-related but nevertheless influence consumers' preferences toward products from the affect-laden countries. Using an appraisal-based approach (Smith and Ellsworth 1985), we operationalize both animosity and affinity as encompassing higher-order affective constructs, comprising a diverse set of emotions. This step is outlined in the method section of Study 2 .

In addition to the diverse set of negative and positive emotions, individuals can also harbor a holistic affective response toward psychological objects. This 'gut feeling' is an aggregated condensate of the diverse emotions and experienced as an integral part (Lerner and Keltner 2000) of the object. Conceptually, it is anchored in the seminal feelings-asinformation theory (Schwarz, 1990), according to which individuals consult, consciously or subconsciously, the valence of their feelings holistically to inform their predispositions toward a psychological object (Pham 2004). In country of origin research, some studies have taken a similar perspective, arguing that consumers hold a holistic affect toward countries that informs their preferences (e.g. Verlegh 2001). In complex globalized marketplaces, it is plausible that consumers use such a simple 'how do I feel about it?'-heuristic to facilitate effortless ordinal judgment and decision-making. As such, incorporating a holistic country affect component is important. While research supports the existence of this affective mental shortcut, measuring holistic affect without referring to a specific emotion (e.g. admiration or attachment) has remained a challenge. In the method section of Study 2, we present a new emoticon-based approach that overcomes this challenge of measuring country affect.

Research that examines both performance-related country images and performanceunrelated emotions is generally scarce, however, even less research has examined how these two pathways interact and jointly affect consumer behavior (Maheswaran et al. 2013). As such, a key aim of the CIP model is to shed light on the questions whether and how performance-based cognitions and performance-unrelated emotions interact to inform 
consumer behavior. Because the two research domains of performance-related and performance-unrelated use of the country cue have almost exclusively been investigated in isolation, limited insight (see Hong and Kang 2006 for an exception) exists as to their relationship. Specifically, these two consumer applications of country information may be congruent or conflicting. For example, Klein et al. (1998) document that animosity negatively affects preferences of Japanese consumers toward Chinese products, despite a favorable performance-related country image of Japan.

How do consumers mentally handle consistency or inconsistency between the two dimensions of CIP, and what is the effect on their behavioral intentions? First, psychologists document that increased consistency between cognitive and affective mental content facilitates processing (Centerbar, Clore, Schnall and Garvin 2008). Accordingly and in line with consistency theories of the mind (Festinger 1957), the impact of both performancerelated and performance-unrelated cues on outcomes should be stronger if the two cues are consistent. Second, research on ambivalent attitudes (Wang, Batra and Chen 2016) documents that when both positive and negative information about a product is accessible, attitudinal ambivalence toward that product can result. This attitudinal ambivalence in turn creates discomfort and affects consumers' predispositions toward the ambivalent product (Pang, Keh, Li and Maheswaran 2017). Including both performance-related and emotional country of origin cues, our CIP model accounts for felt ambivalence and tests its potential role empirically.

We empirically test our developed CIP model in two consecutive studies. Study 1 investigates the proposed imagery-image sub-model. We critically assess the operationalization of country image scales, and derive new parsimonious, reliable and valid measures thereof. Then, in Study 2, we merge the imagery-image sub-model with the second sub-model on country emotions (i.e. animosity, affinity and holistic country affect), and 
empirically validate the unifying CIP model. We review existing measures on affinity and animosity, and develop and validate new scales.

\section{STUDY 1: THE IMAGERY-IMAGE MODEL}

In light of conceptual challenges which confront the study of country image, it comes as no surprise that also the operationalization has often been ambiguous (Roth and Diamantopoulos 2009). Scholars have applied a variety of data collection methods, items and scales to the study of consumers' country images without reaching a consensus. This section addresses these shortcomings.

\section{Measuring Imagery}

The composite nature of consumers' various associations about a country of origin has long presented a challenge for researchers who wish to operationalize it. Specifically, two key challenges exist. Firstly, a decision must be made regarding which associations are relevant for consumers and should therefore be included in a measure, and secondly, whether all consumers attach the same meaning to an association (Steenkamp, Van Trijp and Ten Berge 1994). These issues are usually not included in attempts at measuring these various associations. The following section discusses both challenges, and their implications for the measurement of the concept.

The first challenge concerns the way in which researchers arrive at a valid set of associations for measuring a country's imagery. This issue is almost never discussed in the country image literature. This is astounding because deciding which associations to include or exclude determines the very nature of the construct, and an inappropriate choice is likely to 
result in misleading conclusions. Almost all existing studies take a structured approach to capturing associations, and therefore obtain data through standardized close-ended survey questions for which generic items are used (see Roth and Romeo (1992) for a frequently used measure of this type). Such a structured approach draws on the premise that the same generic country attributes are relevant for all consumers when considering all kinds of products from all countries. In contrast to this approach, research on perceptual mapping documents the necessity and importance of capturing and applying idiosyncratic attributes (John, Loken, Kim and Monga 2006; Steenkamp et al. 1994).

We highlight that the deliberate use of a battery of generic traits neglects the possibility that associations vary across 1) countries of origin, 2) product categories, 3) consumers holding these associations, and 4) time. First, countries are complex entities that differ qualitatively in regard to what attributes consumers associate with them. Second, imagery is likely to vary with product category (Han 1989; Josiassen, Lukas, Whitwell and Assaf 2013; Verlegh et al. 2005) because different associations are relevant depending on the product category considered. For example, assuming that the association 'design' (e.g., Romeo and Roth 1992) is equally relevant for food and fashion is questionable. Yet, almost all studies use such generic measures across product categories. Third, imagery is likely to vary with the person who holds it because nationality and culture may determine the associations of a consumer (Gürhan-Canli and Maheswaran 2000a). Fourth, imagery is likely to vary with time (Gürhan-Canli and Maheswaran 2000a), with Knight, Holdsworth and Mather (2007, p. 109) noting that "it is possible for a product-country image to change over time, sometimes rapidly. Specifically, associations can change because of social or political events (e.g. Klein et al. 1998) or because of economic change (e.g. Taiwan, China and Japan; Amine, Chao and Arnold 2005). In conclusion, imagery measures should be tailored and specific to each and every study. 
Although individuals might form countless beliefs about a country of origin, only those associations that are readily accessible influence decision-making at any given moment (Ajzen 2001). If irrelevant or non-salient associations were used to measure imagery, predictive validity of these associations would be questionable because they are unlikely to be present in the individuals' minds when making purchase decisions (Ajzen and Fishbein 2010). This approach trades methodological convenience for validity and risks neglecting important associations that consumers may hold while capturing irrelevant or erroneous associations. This view is reflected in Jaffe and Nebenzahl's notion (2006, p. 32) when they state that many studies which use a predefined set of items "have one major flaw, they are based on rating questions that stem from what the researchers consider to relate to country image. However, consumers' perceptions do not have to follow the logic of researchers". In response and relying on the literature on perceptual mapping (John et al. 2006; Steenkamp et al. 1994), we suggest an idiographic approach (Bodur et al. 2000) to item development. This study applies qualitative methods in order to identify idiosyncratic associations that individuals hold toward a specific country because "consumers have significantly different country images [for each country]" (Han 1989, p. 222). In accordance with Fishbein and Ajzen (1975) who argue that the initial step in operationalizing cognitive structures is to identify the salient beliefs associated with the psychological object, the present study puts forward that imagery in the mind of the consumer consists of associations which are idiosyncratic to each country.

The second challenge is that most existing studies which set out to measure country image treat all country associations as having equal levels of relevancy and favorability across all consumers and all countries. However, branding research on perceptual mapping documents that consumers' perceived relevancy and favorability of associations vary substantially. Specifically, they vary with regard to 1) how relevant each association is to the specific object, and 2) how favorable each association is to the overall purchase decision (Keller 1993; Schnittka, Sattler and Zenker 2012). Accordingly, we argue that in order to 
understand consumers' associations we need to explore both the degree to which consumers link the association to the origin ('association strength') and how favorable, respectively unfavorable each association is ('association valence'). We define association strength as the subjective relevance of a link between an association and the country (Ajzen and Fishbein 2000). As relevance increases, the particular association becomes more accessible for an individual. Bargh, Chen and Burrows (1996) assert that memory is organized hierarchically with some associations retrieved more easily and faster than others, resulting in higher impact on behavior. Thus, measuring each association's strength is important and provides a proxy for belief accessibility and salience, a key requirement of validity (Ajzen, Nichols and Driver 1995).

Conceptually, a consumer's agreement with the relevance of a link between the country and a specific association is independent from the evaluative reaction toward it. Although being an established approach in attitude theory (Fishbein and Ajzen 2010) and brand research (Park, MacInnis, Priester, Eisingerich and Iacobucci 2010), the perceived valence of associations is almost never separately assessed in country of origin studies (see Gürhan-Canli and Maheswaran 2000a for a notable exception). Against this background, we argue that each consumer's imagery is characterized by a unique association strength and valence composition; in line with Kock, Josiassen and Assaf (2016) we propose a twodimensional space in which imagery is measured. Association valence reflects the subjective degree of positivity or negativity (Ajzen and Fishbein 2000) that a consumer attaches to an association with regard to the purchase decision.

In order to measure the strength and valence of each association, the respondents were asked these questions: How much do you relate this attribute to [country] as a [car maker]? and For you as a consumer considering [buying a car] from [country], would this attribute be rather negative or positive? We measured both items on Likert-scales ranging from not at all 
(0) to very much (6), respectively from very negative (-3) to very positive (3). We assert that an individual's confidence that the country of origin possesses the attribute in question contributes to an individual's imagery in direct proportion to the valence of the association. In concert with Ajzen and Fishbein (1975) and Schnittka et al. (2012), imagery is measured in the following manner:

\section{Country Imagery $=\sum$ Strength $_{\mathrm{i}} \mathrm{X}$ Valence $_{\mathrm{i}}$}

This operationalization of country imagery resembles what Law, Wong and Mobley (1998, p. 745) labelled an "aggregate model" that is "formed as an algebraic composite of its dimensions" which have unit weights themselves (i.e. Strengthi). The more positive the associations, and the more strongly they are held, the bigger the impact on the imagery index.

\section{Method}

While country image and willingness-to-buy (WTB) are measured in the questionnaire with existing reflective scales, the measurement process of the formative country imagery construct entails a qualitative pre-study followed by a quantitative study (Figure 2). The samples were purposefully selected to achieve two aims. First, we aim to compare and validate results from respondents across two countries. Second, we aim to compare results about two countries of origin. Data about two countries of origin are best compared when drawn from one single population. In order to achieve the first aim, we collected data from Danish and American respondents about Germany as an origin of products. In order to achieve the second aim, we collected data from American respondents about both Germany and Italy as origins of products. Across all samples, the product category context was cars.

\section{Qualitative Pre-study}


The aim of the qualitative pre-study is to elicit consumers' various salient associations that they mentally link with Germany and Italy as car makers, and thereby to ensure content specification thereof (Steenkamp et al. 1994). It is important to capture the most relevant and salient associations because each association presents an autonomous causal entity and omission would diminish the validity of the imagery index. The procedure for identifying salient associations needs to conform to four criteria (John et al. 2006). First, methods used to identify the salient associations should be collected from the same population that will be used in the empirical stage. That means, consumers instead of researchers should be asked, and if the empirical study is conducted in more than one country (as it is the case in this research), associations have to be elicited for each country separately. This is necessary because respondents from different countries may hold different sets of associations about the same manufacturing country (as our study will document later). Second, the data used to identify the associations should be based on open-ended questions to allow consumers to use their own formulations. In this study, we asked consumers to describe the respective country as an origin of cars in their own words in semi-structured interviews. Third, the most frequently mentioned associations should be selected for the final association set because they will have the biggest impact on behavior (Ajzen 2001). The item list needs to be truncated to make the final survey length reasonable, thus we established a threshold of top $70 \%$. For our research, we select associations based on frequency and order of mention, and calculate a weighted average thereof for each association. Fourth, it is necessary to retain the exact wording consumers use rather than wording that managers or researchers would commonly use. We clustered synonymous expressions under one label according to a) best representative of the underlying meaning, and b) most frequently mentioned (Bodur et al. 2000).

Semi-structured interviews were conducted in the U.S. and Denmark. In order to identify the associations for Germany and Italy, an U.S. research company was paid to provide 25 U.S. consumers for this stage. The US consumer panel was balanced in gender and 
age. For the Danish consumers, the panel of informants was recruited by the authors through a public street intercept technique in which every tenth individual was approached. Whenever informants expressed their thoughts by using generic labels such as 'good cars' or 'special' to describe a country of origin, the interviewer probed to elicit more specific associations which gave rise to the generic descriptor. This qualitative pre-study yielded seven relevant associations of Danish consumers for Germany, twelve associations of U.S. consumers for Germany, and eleven for Italy. These association sets provide the foundation for the construction of the imagery index.

\section{Quantitative Study}

Data for the empirical analysis of the imagery-image model was also gathered in Denmark (on the origin Germany) and in the U.S. (on Germany and Italy). For the Danish sample, we used a systematic field intercept method and approached potential respondents in regional trains in an urban region in Denmark. A total of 174 usable questionnaires on consumers' perceptions about Germany were collected. For the U.S. sample, we evaluated consumers' predispositions on Germany and Italy using respondents recruited from an U.S. online panel. We collected 260 usable responses on Germany and 244 on Italy. Sample characteristics are shown in Table 1.

--- Insert Table 1 about here ---

Drawing on the developed association sets, a questionnaire was constructed for each sample which contained imagery and image, WTB, as well as age and gender. The indicators for country imagery were measured by multiplying association strength and the corresponding association valence for each association. The final association sets of all three samples as well as their corresponding strength and valence are provided the web appendix. Applying confirmatory tetrad analysis through the partial least squares (PLS) approach indicates that imagery is adequately specified as a formative construct. Because of the causal nature of 
indicators, the interpretation of formative constructs with traditional methods used for the assessment of reflective constructs, such as convergent validity or item reliability, is meaningless. An important statistic for assessing the indicators is the examination of multicollinearity because formative constructs are based on linear equation systems. Analysis of the variance inflation factors (VIF) suggested that two indicators for Germany's imagery, respectively three indicators for Italy exceeded the threshold of 3.33 (Diamantopoulos and Siguaw 2006). After also considering whether deletion would result in loss of meaning, these five indicators were removed from the indicator set.

The measurement of imagery along strength and valence introduces new insights into consumers' memory about countries of origin. Association strength reflects how strongly respondents link a specific association to the country of origin, while the association valence indicates how positive (or negative) respondents evaluate it in the product domain. The associations with the highest strength means are therefore most salient in consumers' minds. The standard deviation of association valence provides the unique insight into how much consumers' perceptions on specific associations vary. While existing studies often assume that each association is equally positive and important, our measure indicates that consumers' evaluation can significantly diverge on given associations. For example, consumers vary considerably on their valence of the emission scandal in both the Danish $(\sigma=1.55)$ and the U.S. sample $(\sigma=1.65)$.

Drawing on Gürhan-Canli and Maheswaran (2000b) and other existing studies that attempt to capture individuals' overall evaluation toward an object (Bagozzi, Batra and Ahuvia 2016; Eagly et al. 1994), we measured country image through three semantic differential items on a 7-point Likert-scale (bad/good; unfavorable/favorable; negative/positive). We measured WTB adapted from Oberecker and Diamantopoulos (2011). In addition, we undertook several steps suggested by Podsakoff, MacKenzie and Podsakoff 
(2012) to mitigate the threat of common method variance (CMV). Specifically, we used proximal separation between predictors and outcomes in the questionnaire, declared anonymity and assured respondents that there were no right or wrong answers. Harman's onefactor test and the correlation analysis of an included marker variable (Josiassen 2011) indicated the robustness of the measurement model to CMV. All measures showed satisfactory composite reliabilities (>.7), average variances extracted (>.5), convergent validity and factor loadings (>.7).

\section{Results}

We empirically examined the imagery-image model through partial least squares structural equation modelling approach (PLS-SEM). PLS-SEM accommodates formative measurement models well and is not constrained by model identification concerns, even if structural models become more complex (Hair, Sarstedt, Ringle and Mena, 2012). We investigated discriminant validity of the reflective constructs by applying Fornell and Larcker's (1981) criterion as well as the heterotrait-monotrait (HTMT) ratio of correlations (Henseler, Ringle and Sarstedt 2015) to all three samples. For every possible pair of reflective constructs in the model, AVE was greater than the squared correlation between them, meeting Fornell and Larcker's (1981) criterion for discriminant validity. As for the HTMT ratio, all possible correlation ratios were below the more conservative threshold of .85 , further indicating discriminant validity (Voorhees, Brady, Calantone and Ramirez 2016).

In order to assure that multicollinearity was not a threat for the reflective constructs, we tested for variance inflation. All VIF were below 4, and thus clearly below the critical threshold of 10, indicating that existing collinearity is not harmful. The model explains a substantial portion of the variance in the dependent variables for all three samples (Table 2). Following standard procedures for obtaining significance scores in PLS-SEM, we applied a nonparametric bootstrapping routine with 5,000 samples and the no sign change option based 
on the $95 \%$ bias-corrected and accelerated confidence interval. Overall, we found strong support for the developed model, and the role of both imagery and image in explaining consumers' purchase intentions. The results indicate that imagery positively relates to image ${ }^{1}$, but also impacts WTB directly. Image in turn positively affects WTB, thus partially mediating the effect imagery has on WTB. These results (Table 2) hold for all three samples and support our contention that cognitive mental content about countries is stored along two distinct, yet related mental representations: country imagery and country image. Importantly, both mental components exert unique effects on consumers' intention to purchase products from the country under investigation, with country image functioning as a mediator between country imagery and WTB. Next, we enhance this initial performance-related model by including the three affective performance-unrelated components.

--- Insert Table 2 about here ---

\section{STUDY 2: THE CIP MODEL}

The aim of Study 2 is to develop the country emotions sub-model, consisting of animosity, affinity and holistic country affect, and to merge it with the imagery-image submodel examined in Study 1. The aggregated CIP model allows for comprehensive empirical examinations of how the country of origin cue colors consumer behavior through both performance-related and performance-unrelated pathways. In order to examine how the two components interact to inform consumer behavior, we include the construct of objective attitudinal ambivalence (Wang et al. 2016) as a moderator variable. In the first stage, the country emotions model requires the application of measures capable of capturing a diverse set of negative and positive emotions that consumers' experience toward a country. In the

\footnotetext{
${ }^{1}$ Investigating this link also serves as a redundancy analysis and documents convergent validity of the formative measurement model.
} 
following, we discuss existing accounts of both animosity and affinity, and derive state-ofthe-art measures thereof. As such, we address Roth and Diamantopoulos (2009, p. 737) notion that "a tailor-made scale for capturing country-related emotions would be most welcome". In an effort to further refine the original animosity scale developed by Klein et al. (1998), Harmeling et al. (2015) provide a comprehensive account of the emotional diversity underlying the animosity construct. Specifically, Harmeling et al. (2015) draw on appraisal theory to distinguish between contending (anger-based) and accommodating (fear-based) emotions that consumers can experience toward specific countries. These emotions are product performance-unrelated and can stem from historical, economic and political events. Harmeling et al.'s (2015) scale is a comprehensive and theory-based measure for consumers' negative emotions experienced toward a country. The selected items are appropriate for the purpose of this study, and therefore adapted.

As for affinity, Oberecker and Diamantopoulos (2011) developed an initial scale that captures consumers' liking, sympathy and attachment toward a specific foreign country. We draw on this initial contribution to develop a more encompassing affinity measure that is capable of capturing a broader range of distinct, yet related positive emotions. By doing so, we address calls for advancing the relatively nascent research stream on affinity (Papadopoulos et al. 2017). Inspired by Thomson, MacInnes and Park (2005), we develop a three-dimensional affinity measure, consisting of the dimensions of sympathy, admiration and attachment. First, sympathy-related emotions reflect a state of liking and is therefore closest to the conceptualization of the existing affinity construct. In a broader socio-psychological context, it reflects the dimension of 'warm feelings' formalized in the stereotype-content model (Fiske, Cuddy, Glick and Xu 2002). Second, the dimension of admiration refers to a group of emotions that imply respect and attributed competence (Fiske et al. 2002). As such, not all countries that are liked are also admired, or vice versa. Third, affinity also manifests in 
feelings of attachment, thereby reflecting an emotional bond that connects the consumer with the country (Park et al. 2010).

Measuring consumers' holistic affect that exists as a 'gut feeling' toward a country presents a key challenge because most approaches would ultimately ask consumers to verbalize their feelings toward the country, thereby tapping into specific emotions (Mauss and Robinson 2009). We present a novel, recently developed measurement approach that uses an emoticon scale (Roberts, Roberts, Danaher and Raghavan 2015), asking respondents to indicate the overall valence of their feelings toward the country by selecting one of five emoticon faces, ranging from an unhappy to a happy smiley face. This approach overcomes issues of forced verbalization, allows for a more intuitive way of expressing affect, and simultaneously obviates CMV. By doing so, we address research documenting that consumers tend to communicate country emotions nonverbally (Herz and Diamantopoulos 2013). Further, we included resistance to positive information (RPI) as another outcome variable. In a globalized world with highly pervasive information technologies, consumers are continuously exposed to new information about products associated with specific countries. Researchers know little about how consumers factor new information into their existing attitudes and behavior although initial studies indicate that new information, positive and negative, drives financial performance (Xiong and Bharadwaj 2013). Research building on attitude change provides hints that a person's predispositions toward an object may affect the person's inclination to believe in new positive and negative information about that object (Klein and Ahluwalia 2005). This conceptualization is supported by consistency theories (Festinger 1957), according to which people seek consistency when integrating new information and therefore are more likely to reject new information that is inconsistent. Thus, higher levels of our CIP components, except animosity, should facilitate the integration of new positive, and therefore consistent, information.

\section{Method}


A full list of all variables, and their respective items used in this study are provided in Table 3. We collected data from 991 U.S. respondents through an online panel (Mechanical Turk) with a balance in terms of gender and age. In order to demonstrate the applicability of our model across countries and product categories, we collected data on three new countries and three new product categories, specifically China (smartphones), United Kingdom (furniture) and Israel (watches). The three countries were equally split among the 991 respondents and the questionnaire design is similar to the one used in Study 1.

\section{Measures}

To capture the imagery-image model, we used the same scales as in Study 1. Thus, we again followed the imagery measurement process (Figure 2) and conducted a qualitative prestudy to reveal consumers' salient associations with the three countries in the respective product categories (associations sets are available on request). For each respondent, a formative imagery index was then calculated across all strength-valence combinations of associations. To capture the affective country bias model, we developed the measures for animosity and affinity by deriving an initial set of items from existing literature. For animosity, we drew on Harmeling et al. (2015) while for affinity, we derived items from various studies that investigate positive emotions that consumers can experience toward a psychological object (e.g., Park et al. 2010; Thomson et al. 2005). We assessed all items through initial exploratory factor analyses, followed by confirmatory factor analyses to assess dimensionality and validity of the animosity and affinity construct. Specifically, we conducted an iterated $\chi^{2}$-difference test by selecting the item with the lowest item-to-total correlation, stopping only when the $\chi^{2}$-difference tests showed no difference or the adjusted goodness-offit index did not increase. Further, high inter-item correlations indicated item redundancy, and respective items were deleted. We then compared the second-order measurement models of animosity (two dimensions) and affinity (three dimensions) with alternative unidimensional 
first-order constructs. Because the models are nested, model fit indices are comparable and indicate a superior fit for the second-order measurement models, thus supporting our conceptual contention. RPI was measured by adapting the scale from Eisingerich, Rubera, Seifert and Bhardwaj (2011). The final items, their loadings, and statistical are shown in Table 3.

\section{--- Insert Table 3 about here ---}

In order to measure objective ambivalence between country image and holistic country affect, we adapted the formula for the similarity intensity model (SIM; Thompson, Zanna and Griffin 1995). The computation equation of SIM is $\mathrm{OA}=[\mathrm{C}+\mathrm{N}] / 2-|\mathrm{P}-\mathrm{N}|$, where $\mathrm{OA}$ is the objective ambivalence, $\mathrm{C}$ represents the positive cognitive predisposition (i.e. country image), and A reflects the (recoded) affective predisposition (i.e. holistic country affect).

\section{Results}

We first assessed the data against the necessary assumptions, finding both skewness and kurtosis within acceptable limits for all variables (i.e. between -1 to 1). As for all multiitem measurement models, we found satisfactory levels of reliability and validity, along with adequate factor loadings (CR>.7; AVE >.5; factor loadings $>.7)$. As we modelled animosity and affinity as reflective higher-order constructs, we tested whether the information captured by each of the dimensions was distinct from each other. Two heuristics, the Fornell-Larcker criterion and the HTMT ratio indicate discriminant validity between the dimensions, thus providing empirical support for our multidimensional conceptualization. We then tested all other multi-item variables with the same two heuristics, and found discriminant validity for every pair of constructs.

Next, we tested the structural relationships in the CIP model (Figure 3) through a SEM analysis in AMOS 24. Note that we first tested the CIP model with affinity and animosity, but without holistic country affect in order examine the direct effect the specific emotions have on outcome variables. The model fits the data well $\left(\chi^{2} / \mathrm{df}=4,267\right.$; confirmatory fit index $[\mathrm{CFI}]=$ 
.970 ; non-normed fit index $[\mathrm{NNFI}]=.965$; root mean squared error of approximation $[\mathrm{RMSEA}]=.057 ;$ standardized root mean residual $[\mathrm{SRMR}]=.084)$ and accounts for a significant amount of explained variance in the dependent variables $\left(\mathrm{R}^{2}\right.$ country image $=.45$; $\left.\mathrm{R}^{2} \mathrm{WTB}=.46 ; \mathrm{R}^{2} \mathrm{RPI}=.37\right)$. Importantly, explained variance is higher for this integrative CIP model than if the first sub-model $\left(\mathrm{R}^{2}\right.$ country image $\left.=.36 ; \mathrm{R}^{2} \mathrm{WTB}=.43 ; \mathrm{R}^{2} \mathrm{RPI}=.31\right)$ aor the second sub-model $\left(\mathrm{R}^{2} \mathrm{WTB}=.26 ; \mathrm{R}^{2} \mathrm{RPI}=.24\right)$ are examined in isolation. These results indicate that both performance-related cognitions and performance-unrelated emotions are important to include to comprehensively understand the effects of the country of origin cue on consumer behavior. Specifically, animosity and affinity drive behavioral intentions directly but also indirectly through informing the performance-related country image (Figure 3). Interestingly, animosity and affinity show valence-corresponding effects: animosity relates positively to RPI $(.27, \mathrm{p}<.001)$ while affinity relates positively to WTB $(.23, \mathrm{p}<.001)$.

\section{--- Insert Figure 3 about here ---}

Next, we entered the holistic country affect component into the CIP model in order to test how it relates to animosity, affinity and outcomes, and whether it presents an appropriate alternative to the complex-emotions scales of animosity and affinity. Specifically, for some country of origin studies, measuring affect toward a country may not be the key goal, though, incorporating a short but reliable measure like the emoticon scale can provide additional insights. Holistic country affect is conceptualized as a condensate of the complex emotions represented by animosity and affinity, and used as a heuristic cue by consumers to construct preferences. As such, we tested its role as a mediator between animosity, affinity and outcome variables. This model fits the data well $\left(\chi^{2} / \mathrm{df}=4,105 ; \mathrm{CFI}=.970 ; \mathrm{NNFI}=.965 ;\right.$ RMSEA $=$ $.056 ; \mathrm{SRMR}=.056)$ and explains more variance in two of the three dependent variables $\left(\mathrm{R}^{2}\right.$ : country image $=.50 ; \mathrm{WTB}=.49 ; \mathrm{RPI}=.32)$. An analysis of the standardized path coefficients documents that both animosity $(-.36, \mathrm{p}<.001)$ and affinity $(.51, \mathrm{p}<.001)$ relate to holistic 
country affect, and together with imagery $(.12, \mathrm{p}<.001)$, predict considerable variance of it $\left(\mathrm{R}^{2}\right.$ $=.64)$. In turn, holistic country affect significantly relates to country image $(.42, \mathrm{p}<.001)$, WTB $(.32, \mathrm{p}<.001)$ and RPI $(-.12, \mathrm{p}<.01)$, thereby documenting that holistic affect drives the performance-related evaluation of a country as well as consumers' intentions toward products from that country.

Next, we examined the interaction between the cognitive performance-related and affective performance-unrelated components. Specifically, we were interested in how the existence of objective ambivalence toward the country of origin, reflected by varying degrees of consistency between country image and holistic country affect, interacts with the main effects we identified. We conducted four multiple regression analyses that regressed the respective dependent variable (i.e. WTB or RPI) onto country image, respectively holistic country affect, objective ambivalence and the product term of the latter two. Significant interaction effects of ambivalence are found in three out of the four moderation analyses, thus suggesting the presence of an interaction effect. Specifically, the interaction effect indicates that the higher the ambivalence between the cognitive and affective component, the weaker is the effect of both country image and holistic country affect on WTB (for country image, the standardized interaction coefficient is $-.19, \mathrm{p}<.001$; for country affect, the coefficient is -.37 , $\mathrm{p}<.05)$. We further calculated the effect of both country image and country affect on WTB on three different levels of ambivalence (Jaccard and Turrisi 2003), finding that the mitigating effect increases from low to high levels (as indicated by decreasing standardized path coefficients). In addition, we examined the direct effect of country image $(.57, \mathrm{p}<.001)$ and holistic country affect $(.58, \mathrm{p}<.001)$ on WTB in relation to the interaction effect because the effect size of a moderation is to be understood in direct proportion to its corresponding main effect. We find that the relative interaction effect is larger for country affect (-.37 to .58) than for country image (-.19 to .57), thus suggesting that higher ambivalence mitigates the effect of country affect more than the effect of country image on WTB. In consequence, the relative 
importance of country image increases if ambivalence increases. These results provide further evidence of the necessity to include both performance-related cognition and performanceunrelated affect into a comprehensive examination of country of origin effects.

\section{DISCUSSION}

For both academicians and managers who want to examine the potential of the country of origin cue, the starting point is understanding and measuring how it manifests in consumers' minds. Active strategy-building, management and communication of this cue is only possible if managers can examine the actual mental content held in consumers' minds and how they use it to inform purchase decisions. Countless studies have significantly contributed to advance this important research field along two main avenues of inquiry: country image and country emotions. Yet, no unifying theory-based account exists on how they interact and how to conceptually and operationally integrate them. The present study addresses this important issue by introducing the CIP model. We theoretically derive, and empirically validate five components which are separated into cognitive performance-related and affective performance-unrelated components. This universal understanding and the reported findings have important implications for research and practice. We first discuss the big picture implications of this research for theory and then provide detailed and tailored implications for practice. We then conclude with potential limitations and an outline of intriguing future research paths. 


\section{Theoretical Implications}

The first big picture implication of the CIP is that there is not one 'country of origin image' but five conceptually and empirically distinct components. The fact that we observe this pattern with data from five different countries of origin and four different product categories suggests that this model is robust. The findings suggest that the high number of diverse accounts of the country of origin cue in the literature is justified, but instead of arguing in favor of one account, and against another, a unifying model in which these accounts exist as complementary components is conceptually viable and empirically validated. The five components fit in a hierarchical structure, in which complex thoughts (imagery) and feelings (animosity and affinity) feed into a more holistic cognitive evaluation (image), and an affective response (holistic affect) to the country of origin.

The second theoretical implication is that a comprehensive consumer-based examination of the country of origin cue needs to include both cognitive performance-related and affective performance-unrelated components. Our findings in the CIP model shed light on the causal link between performance-unrelated affect and performance-related image. Specifically, we document that affect largely and significantly impacts performance-related image, thereby reiterating the need to include both types into a comprehensive examination thereof. Importantly, we document that ambivalence between the two types of cues impacts the extent to which each of them informs consumers' predispositions. Looking at either performance-related or performance-unrelated cues provides an incomplete picture at best, and both researchers and managers need to be aware of the potential reciprocal effects between the two types of components. Specifically, our findings document that both types exert independent effects on consumers' predispositions, but inconsistency between them (e.g. a favorable image combined with an unfavorable affect) limits these effects. As such, inconsistency may result in lower relevance of the country of origin cue for consumers' 
choices, partly because this inconsistency provides only ambiguous implications for consumers.

The third theoretical implication pertains to the conceptualization and operationalization of country imagery. Our results document that the associations that make up an imagery vary with the country of origin, the consumer's nationality and the product category. In addition, research documents that CIP also vary across time (Gürhan-Canli and Maheswaran 2000a). Capturing idiosyncratic associations, the imagery measure is amenable to address this specificity and should therefore be specific for each and every study because there is no a priori reason to expect that all countries are represented by the same set of associations in all consumers' minds at each point in time. Reiterating earlier notions (Roth and Diamantopoulos 2009), we point out that the neglect of country image specificity is an important reason for the inconsistencies of the country of origin effect reported in the literature. Hence, our developed imagery measure can contribute to mitigate the ramifications of this inconsistency.

A fourth theoretical implication with broad scope concerns the structure of the CIP that is amenable to the application of mental dual-processing theories. Specifically, the five CIP components can be interpreted in the tradition of systematic and heuristic processing (Chaiken 1980). This consideration leads to the interesting contention that mental processing can be understood as a function of the mental content that consumers hold in their minds about countries. While country of origin information in the condensed form of image and holistic affect may be used as a heuristic decision-supporting cue by consumers, our approach also allows for viewing country of origin cues as being systematically processed in the form of imagery, animosity and affinity. Through this lens of attitude change theory, we also suggest that affect may predispose consumers to factor only congenial new information into their imagery. Specifically, if the new information is congenial with country image and 
holistic affect, consumers may have a higher propensity to factor this information into their imagery compared to when it is not (Hart, Albarracin, Eagly, Brechan, Lindberg and Merrill 2009). These possibilities reiterate the need for international marketing researchers to implement affect into studies on country of origin content.

\section{Managerial Implications}

A big picture implication for both managers and researchers is that our study guides both researchers and managers in their choice of the appropriate measurement of the country of origin cue. Different managerial problems of the country of origin cue have different purposes, and therefore demand different measures that vary across a) what mental content is measured, and b) at which level of detail it is captured (Figure 4). We provide guidelines on when to use which measure, and can therefore hopefully assist managers and researchers in their future efforts to grasp this complex yet crucial research topic. We discuss four steps that assist in choosing the right construct to measure.

--- Insert Figure 4 about here ---

First, for many researchers and managers the key aim is to identify the associations that consumers link with a particular country of origin because strong images sustainably distinguish products and result in favorable consumer preferences in the globalized marketplace. For this purpose, the construct of country imagery should be applied. While the country image measure only reveals how positively or negatively a country is evaluated, the imagery measure enables managers to understand which particular associations determine why a particular country of origin is superior or inferior to another. Such insights enable managers to identify the key strengths and weaknesses among the associations that underlie the respective country cue, thereby assisting them in leveraging the country cue for any given product and context. Specifically, for managers the imagery measure identifies which specific associations that consumers actually hold and use in their purchase decisions. Importantly, 
these associations may differ among consumers from different export markets and for different products, thus highlighting the need to capture a specific imagery rather than relying on a generic measure. Another key strength of the imagery concept is that it enables cardinal comparisons among countries with qualitatively different associations, thereby solving the existing trade-off between comparability and idiosyncrasy of country of origin measures. As many international marketing managers have the opportunity to select a country of origin for their products, imagery can assist in selecting the optimal country cue for any respective product category and export market. Because all variables are quantified, this selection process is objective and transparent for the manager.

Second, even if studying the country of origin cue is not the key focus, including it in the questionnaires is often of interest. In such a case, the country image measure should be applied. Our findings document that country image serves as the evaluative condensate of country imagery and mediates the effect imagery has on consumers' predispositions, thereby explaining a significant proportion of the country of origin cue's impact. Together, country imagery and country image provide the most detailed, yet easy to administer measures of cognitive performance-related country of origin content. Third, we document that an account of the country of origin cue is incomplete if performance-unrelated affect is not included. For managers, being aware of and understanding consumers' affective responses to the country directly, and not merely its products, is vital because these emotions can impact consumers' preference without being under the control of the company. We provide three measures to understand this important issue: animosity, affinity and holistic country affect. If the aim is to gain a comprehensive understanding of the emotional landscape that consumers harbor toward the country that the company uses as the country of origin, we advise to measure animosity and affinity. Specifically, animosity captures the dimensions of anger- and fear-related emotions while affinity comprises the three dimensions of admiration, like and attachment. This detailed appraisal-based lens on country-related emotions is better in explaining the 
sources of consumer behavior than generic affect measures as it accounts for the diversity of emotions beyond similarly valenced emotions. Understanding that animosity is rooted in fear for one country but in anger for another has important implication for how the country is perceived by consumers: Anger-based animosity may motivate consumers' to actively boycott its products, while fear-based animosity may result in avoidance.

Fourth, even if examining the diversity of country-related emotions is not a key goal when examining the country of origin cue, including an affective performance-unrelated measure complementary to its cognitive performance-related counterpart is advisable. Our findings document that the holistic country affect, measured through an emoticon, approximates an affective amalgam of animosity and affinity, and predicts consumers' predispositions. Because of its parsimonious and intuitive nature, the emoticon measure can be conveniently used by marketing managers who want to capture the sentiment of their used country cue in different export markets. In conclusion, our developed measures allow a theory-based yet simple application of the country of origin cue in various research and management settings, ranging from parsimonious to very detailed along the cognitive and affective dimension (Figure 4). For researchers and managers examining the country of origin cue of a particular country in detail, our CIP model allows for studying the complexity of this topic holistically.

\section{FUTURE RESEARCH AND LIMITATIONS}

The insights generated in this study lend themselves to intriguing new research opportunities. First, the CIP allows for testing the impact of inconsistencies in the country of origin cue on consumers' responses, an often neglected issue in international marketing research. Specifically, inconsistencies between the cognitive and affective components create ambivalence, which in turn undermines the relevance of the country of origin cue for 
consumers. Testing this initial result across different countries and product categories may help understand when the country cue matters and thus significantly contributes to the ongoing discussion on the relevance of the country of origin cue for consumers. In a related vein, future research could examine consumers with varying levels of dialecticism which may react differently to inconsistency (Wang et al. 2016) between the two components Second, our CIP model would benefit from including performance-unrelated associations (i.e. complementary to the performance-related imagery) because these associations serve as appraisals for animosity and affinity. Such an examination would not only complement the CIP but be insightful for various other disciplines in which predispositions toward countries are of interest. Third, the imagery construct is amenable to comparing data from different cultures and different points in time in a quantitative manner. While existing country of origin image measures would only be able to detect differences in terms of valence (i.e., how positive or negative a country image is across countries), the imagery construct provides more detailed insights while ensuring comparisons. Future research should make use of this advantage and capture manifold imageries of countries in order to understand differences in culture and time. By doing so, a superior data basis for international companies can be generated with the aim of planning and executing tailored marketing activities that involve the country cue.

Fourth, the current study relies on self-reports for understanding the components of the CIP. While this approach is meaningful and reliable, indirect measures could complement future research. In particular, implicit association tests (IAT; Greenwald, McGhee and Schwartz 1998) could be employed to measure association strength. While we approximated strength in the qualitative study, IAT's could also supplement the quantitative data collection. An advantage would be that imagery is then measured trough two different methods, thereby mitigating CMV. Fifth, we suggest that future research tests the predictive validity of the developed country imagery construct against a widely used generic measure (e.g., Roth and 
Romeo 1992) across countries and groups of respondents. While this study documents the predictive validity of the CIP, comparing it against existing studies would enhance its validity and future usefulness. Sixth, and going beyond international marketing, we call for research on applying the CIP to another important, yet equally complex research field: brand image. Literature on this topic may also be enhanced conceptually and empirically by examining cognitive and affective components of the brand together. Importantly, because country image and brand image are often intertwined, a meta-CIP that comprises both areas could help to understand interrelationships better. In conclusion, adopting a universal perspective that synthesizes the complexity of consumers' mental country of origin structures is critical to advance theory and practice of country cue applications.

\section{REFERENCES}

Ajzen, I. (1991). The theory of planned behavior. Organizational Behavior and Human Decision Processes, 50, 179-211.

Ajzen, I. (2001). Nature and operation of attitudes. Annual Review of Psychology, 52, 27-58.

Ajzen, I., \& Fishbein, M. (2000). Attitudes and the attitude-behavior relation: Reasoned and automatic processes. European Review of Social Psychology, 11(1), 1-33.

Ajzen, I., Nichols, A. J., \& Driver, B. L. (1995). Identifying salient beliefs about leisure activities: Frequency of elicitation versus response latency. Journal of Applied Social Psychology, 25(16), 1391-1410.

Amine, L. S., Chao, M. C., \& Arnold, M. J. (2005). Executive insights: Exploring the practical effects of country of origin, animosity, and price-quality issues: Two case studies of Taiwan and Acer in China. Journal of International Marketing, 13(2), 114-150. 
Bagozzi, R. P., Batra, R., \& Ahuvia, A. (2016). Brand love: development and validation of a practical scale. Marketing Letters, 28(1), 1-14.

Bagozzi, R. P., Gopinath, M., \& Nyer, P. U. (1999). The role of emotions in marketing. Journal of the Academy of Marketing Science, 27(2), 184-206.

Bargh, J. A., Chen, M., \& Burrows, L. (1996). Automaticity of social behavior: Direct effects of trait construct and stereotype activation on action. Journal of Personality and Social Psychology, 71(2), 230-244.

Bodur, H. O., Brinberg, D., \& Coupey, E. (2000). Belief, affect, and attitude: Alternative models of the determinants of attitude. Journal of Consumer Psychology, 9(1), 1728.

Centerbar, D. B., Schnall, S., Clore, G. L., \& Garvin, E. D. (2008). Affective incoherence: when affective concepts and embodied reactions clash. Journal of Personality and Social Psychology, 94(4), 560-578.

Chaiken, S. (1980). Heuristic versus systematic information processing and the use of source versus message cues in persuasion. Journal of Personality and Social Psychology, 39(5), 752-766.

Chen, C. Y., Mathur, P., \& Maheswaran, D. (2014). The effects of country-related affect on product evaluations. Journal of Consumer Research, 41, 1033-1046.

Diamantopoulos, A., \& Siguaw, J. A. (2006). Formative versus Reflective Indicators in Organizational Measure Development. British Journal of Management, 17, 263-282.

Durand, A., Turkina, E., \& Robson, M. (2016). Psychic distance and country image in exporter-importer relationships. Journal of International Marketing, 24(3), 31-57. 
Eagly, A. H., \& Chaiken, S. (1993). The Psychology of Attitudes. Fort Warcourt Brace Jovanovich.

Eagly, A. H., Mladinic, A., \& Otto, S. (1994). Cognitive and affective bases of attitudes toward social groups and social policies. Journal of Experimental Social Psychology, 30, 113-137.

Eisingerich, A. B., Rubera, G., Seifert, M., \& Bhardwaj, G. (2011). Doing good and doing better despite negative information?: The role of corporate social responsibility in consumer resistance to negative information. Journal of Service Research, 14(1), 60-75.

Festinger, L. (1957). A theory of cognitive dissonance. Evanston, IL: Row, Peterson.

Fishbein, M., \& Ajzen, I. (1975). Belief, Attitude, Intention, and Behavior: An Introduction to Theory and Research. Readin, MA: Addison-Wesley.

Fishbein, M., \& Ajzen, I. (2010). Predicting and Changing Behavior: The reasoned action approach. Taylor \& Francis.

Fiske, S. T., Cuddy, A. J., Glick, P., \& Xu, J. (2002). A model of (often mixed) stereotype content: competence and warmth respectively follow from perceived status and competition. Journal of Personality and Social Psychology, 82(6), 878-902.

Fong, C. M., Lee, C. L., \& Du, Y. (2014). Consumer animosity, country of origin, and foreign entry-mode choice: a cross-country investigation. Journal of International Marketing, 22(1), 62-76.

Fornell, C., \& Larcker, D.F. (1981). Evaluating structural equation models with unobservable variables and measurement error. Journal of Marketing Research, 18(1), 39-50. 
Gürhan-Canli, Z., Sarial-Abi, G., \& Hayran, C. (2018). Consumers and brands across the globe: research synthesis and new directions. Journal of International Marketing, 26(1), 96-117.

Gürhan-Canli, Z., \& Maheswaran, D. (2000a). Cultural variations in country of origin effects. Journal of Marketing Research, 37(August), 309-317.

Gürhan-Canli, Z., \& Maheswaran, D. (2000b). Determinants of country-of-origin evaluations. Journal of Consumer Research, 27(1), 96-108.

Greenwald, A. G., McGhee, D. E., \& Schwartz, J. L. K. (1998). Measuring individual differences in implicit cognition: The Implicit Association Test. Journal of Personality and Social Psychology, 74, 1464-1480.

Hair, J. F., Sarstedt, M., Ringle, C. M., \& Mena, J. A. (2012). An assessment of the use of partial least squares structural equation modeling in marketing research. Journal of the Academy of Marketing Science, 40(3), 414-433.

Han, C. M. (1989). Country image: Halo or summary construct? Journal of Marketing Research, 26(2), 222-229.

Harmeling, C. M., Magnusson, P., \& Singh, N. (2015). Beyond anger: A deeper look at consumer animosity. Journal of International Business Studies, 46(6), 676-693.

Hart, W., Albarracín, D., Eagly, A. H., Brechan, I., Lindberg, M. J., \& Merrill, L. (2009). Feeling validated versus being correct: A meta-analysis of selective exposure to information. Psychological Bulletin, 135(4), 555-588.

Henseler, J., Ringle, C.M., \& Sarstedt, M. (2015). A new criterion for assessing discriminant validity in variance-based structural equation modeling. Journal of the Academy of Marketing Science, 43, 115-135. 
Herz, M., \& Diamantopoulos, A. (2017). I use it but will tell you that I don't: Consumers' country-of-origin cue usage denial. Journal of International Marketing, 25(2), $52-71$.

Herz, M. F., \& Diamantopoulos, A. (2013). Country-specific associations made by consumers: A dual-coding theory perspective. Journal of International Marketing, 21(3), 95121.

Hong, S. T., \& Kang, D. K. (2006). Country-of-origin influences on product evaluations: The impact of animosity and perceptions of industriousness brutality on judgments of typical and atypical products. Journal of Consumer Psychology, 16(3), 232-239.

Jaccard, J. and Turrisi, R. (2003). Interaction Effects in Multiple Regression. Thousand Oaks, CA: Sage Publications.

Jaffe, E. D., \& Nebenzahl, I. D. (2006). National Image and Competitive Advantage. Copenhagen Business School Press: Copenhagen, Denmark.

John, D. R., Loken, B., Kim, K., \& Monga, A. B. (2006). Brand concept maps: A methodology for identifying brand association networks. Journal of Marketing Research, 43(4), 549-563.

Josiassen, A., \& Harzing, A. W. (2008).Descending from the ivory tower: reflections on the relevance and future of country-of-origin research. European Management Review, 5(4), 264-270.

Josiassen, A., Lukas, B. A., Whitwell, G. J., \& Assaf, A. G. (2013). The halo model of origin images: Conceptualisation and initial empirical test. Journal of Consumer Behaviour, 12(4), 253-266. 
Josiassen, A. (2011). Consumer disidentification and its effects on domestic product purchases: An empirical investigation in the Netherlands. Journal of Marketing, 75(2), 124140.

Keller, K. L. (1993). Conceptualizing, measuring, and managing customer-based brand equity. Journal of Marketing, 57(1), 1-22.

Klein, J. G., \& Ahluwalia, R. (2005). Negativity in the evaluation of political candidates. Journal of Marketing, 69(1), 131-142.

Klein, J. G., Ettenson, R., \& Morris, M. D. (1998). The animosity model of foreign product purchase: An empirical test in the people's republic of china. Journal of Marketing, 62(January), 89-100.

Knight, J. G., Holdsworth, D. K., \& Mather, D. W. (2007). Country-of-origin and choice of food imports: an in-depth study of European distribution channel gatekeepers. Journal of International Business Studies, 38(1), 107-125.

Kock, F., Josiassen, A., \& Assaf, A. G. (2016). Advancing destination image: The destination content model. Annals of Tourism Research, 61, 28-44.

Koschate-Fischer, N., Diamantopoulos, A., \& Oldenkotte, K. (2012). Are consumers really willing to pay more for a favorable country image? A study of country-of-origin effects on willingness to pay. Journal of International Marketing, 20(1), 19-41.

Kotler, P., Haider, D. H., \& Rein, I. (1993). Marketing Places. New York: The Free Press.

Law, K. S., Wong, C., \& Mobley, W. H. (1998). Toward a taxonomy of multidimensional constructs. Academy of Management Review, 23(4), 741-755. 
Lerner, J. S., \& Keltner, D. (2000). Beyond valence: Toward a model of emotionspecific influences on judgement and choice. Cognition and Emotion, 14(4), 473-493.

Lerner, J. S., Li, Y., Valdesolo, P., \& Kassam, K. S. (2015). Emotion and decision making. Annual Review of Psychology, 66, 799-823.

Magnusson, P., Krishnan, V., Westjohn, S. A., \& Zdravkovic, S. (2014). The spillover effects of prototype brand transgressions on country image and related brands. Journal of International Marketing, 22(1), 21-38.

Maheswaran, D. (1994). Country of origin as a stereotype: Effects of consumer expertise and attribute strength on product evaluations. Journal of Consumer Research, 21(2), $354-365$.

Maheswaran, D., \& Chen, C. Y. (2006). Nation equity: Incidental emotions in country of-origin effects. Journal of Consumer Research, 33, 370-376.

Maheswaran, D., Chen, C., \& He, J. (2013). Nation equity: Integrating the multiple dimensions of country of origin effects. Marketing Research Review, 10, 153-189.

Martin, I. M., \& Eroglu, S. (1993). Measuring a multi-dimensional construct: Country image. Journal of Business Research, 28, 191-201.

Mauss, I. B., \& Robinson, M. D. (2009). Measures of emotion: A review. Cognition and Emotion, 23(2), 209-237.

Nielsen (2016). Nearly 75\% of Global Consumers List Brand Origin as Key Purchase Driver. http://www.nielsen.com/us/en/press-room/2016/nielsen-75-percent-of-globalconsumers-list-brand-origin-as-key-purchase-driver.html. 
Oberecker, E. M., \& Diamantopoulos, A. (2011). Consumers' emotional bonds with foreign countries: Does consumer affinity affect behavioral intentions? Journal of International Marketing, 19(2), 45-72.

Pang, J., Keh, H. T., Li, X., \& Maheswaran, D. (2017). "Every coin has two sides”: The effects of dialectical thinking and attitudinal ambivalence on psychological discomfort and consumer choice. Journal of Consumer Psychology, 27(2), 218-230.

Papadopoulos, N., Banna, A. E., \& Murphy, S. A. (2017). Old country passions: an international examination of country image, animosity, and affinity among ethnic consumers. Journal of International Marketing, 25(3), 61-82.

Parameswaran, R., \& Pisharodi, R. M. (1994). Facets of country of origin image: An empirical assessment. Journal of Advertising, 23(1), 43-56.

Park, C. W., MacInnis, D. J., Priester, J., Eisingerich, A. B., \& Iacobucci, D. (2010). Brand attachment and brand attitude strength: Conceptual and empirical differentiation of two critical brand equity drivers. Journal of Marketing, 74(1), 1-17.

Pham, M.T. (2004). The logic of feeling. Journal of Consumer Psychology, 14(4), $360-369$.

Podsakoff, P. M., MacKenzie, S. B., \& Podsakoff, N. P. (2012). Sources of method bias in social science research and recommendations on how to control it. Annual Review of Psychology, 63, 539-569.

Roberts, K., Roberts, J. H., Danaher, P. J., \& Raghavan, R. (2015). Practice Prize Paper-Incorporating Emotions into Evaluation and Choice Models: Application to Kmart Australia. Marketing Science, 34(6), 815-824.

Roth, K. P., \& Diamantopoulos, A. (2009). Advancing the country image construct. Journal of Business Research, 62(7), 726-740. 
Roth, M. S., \& Romeo, J. B. (1992). Matching product category and country Image perceptions: A framework for managing country-of-origin effects. Journal of International Business Studies, 23(3), 477-497.

Samiee, S., \& Chabowski, B. R. (2012). Knowledge structure in international marketing: a multi-method bibliometric analysis. Journal of the Academy of Marketing Science, 40(2), 364-386.

Schnittka, O., Sattler, H., \& Zenker, S. (2012). Advanced brand concept maps: A new approach for evaluating the favorability of brand association networks. International Journal of Research in Marketing, 29(3), 265-274.

Schwarz, N. (1990). Feelings as Information: Informational and Motivational Functions of Affective States. Guilford Press.

Shankarmahesh, M. N. (2006). Consumer ethnocentrism: An integrative review of its antecedents and consequences. International Marketing Review, 23(2), 146-172.

Smith, C. A., \& Ellsworth, P. C. (1985). Patterns of cognitive appraisal in emotions. Journal of Personality and Social Psychology, 48(4), 813-838.

Steenkamp, J. B. E., Van Trijp, H. C., \& Ten Berge, J. M. (1994). Perceptual mapping based on idiosyncratic sets of attributes. Journal of Marketing Research, 31(1) 15-27.

Thompson, M. M., Zanna, M. P., \& Griffin, D. W. (1995). Let's not be indifferent about (attitudinal) ambivalence. In R. E. Petty \& J. A. Krosnick (Eds.), Attitude strength: Antecedents and consequences. Mahwah: Erlbaum.

Thomson, M., MacInnis, D. J., \& Park, C. W. (2005). The ties that bind: Measuring the strength of consumers' emotional attachments to brands. Journal of Consumer Psychology, 15(1), 77-91.

Verlegh, P. W. J., \& Steenkamp, J. E. M. (1999). A review and meta-analysis of country-of-origin research. Journal of Economic Psychology, 20, 521-546. 
Verlegh, P. W. J. (2001). Country-of-origin effects on consumer product evaluations. Wageningen University.

Verlegh, P. W. J, Steenkamp, J. E. M., \& Meulenberg, M. T. G. (2005). Country-oforigin effects in consumer processing of advertising claims. International Journal of Research in Marketing, 22, 127-139.

Voorhees, C. M., Brady, M. K., Calantone, R., \& Ramirez, E. (2016). Discriminant validity testing in marketing: an analysis, causes for concern, and proposed remedies. Journal of the Academy of Marketing Science, 44(1), 119-134.

Wang, H., Batra, R., \& Chen, Z. (2016). The moderating role of dialecticism in consumer responses to product information. Journal of Consumer Psychology, 26(3), 381394.

Xiong, G. \& Bharadwaj, S. (2013). Asymmetric roles of advertising and marketing capability in financial returns to news: Turning bad into good and good into great. Journal of Marketing Research, 50(December), 706-724.

Zeugner-Roth, K. P., Žabkar, V., \& Diamantopoulos, A. (2015). Consumer ethnocentrism, national identity, and consumer cosmopolitanism as drivers of consumer behavior: A social identity theory perspective. Journal of International Marketing, 23(2), 2554.

\section{TABLES}

Table 1: Sample characteristics Study 1

\begin{tabular}{|l|c|c|c|}
\hline Respondents & Denmark & U.S. & U.S. \\
\hline Country context & Germany & Germany & Italy \\
\hline Sample size & 174 & 260 & 244 \\
\hline Age $(\%)$ & & & 35.8 \\
\hline$>30$ years & 58.7 & 37.7 & \\
\hline
\end{tabular}




\begin{tabular}{|l|c|c|c|}
\hline $30-49$ years & 33.3 & 45.9 & 46.8 \\
\hline$<49$ years & 8.0 & 16.4 & 17.4 \\
\hline Gender $(\boldsymbol{\%})$ & & & \\
\hline Female & 55.2 & 55.1 & 55.0 \\
\hline Male & 44.8 & 44.9 & 45.0 \\
\hline
\end{tabular}

Table 2: Structural model results for Study 1

\begin{tabular}{|c|c|c|c|}
\hline & \multicolumn{3}{|c|}{ Sample } \\
\hline & Germany (DK) & Germany (U.S.) & Italy (U.S.) \\
\hline Imagery $\rightarrow$ Image & $.65^{* *}$ & $.72^{* *}$ & $.63^{* *}$ \\
\hline Imagery $\rightarrow$ WTB & $.13 \mathrm{n} . \mathrm{s}$. & $.35^{* *}$ & $.26^{* *}$ \\
\hline Image $\rightarrow$ WTB & $.47^{* *}$ & $.30^{* *}$ & $.20^{* *}$ \\
\hline Imagery $\rightarrow$ WTB (total effects) & $.31^{* *}$ & $.57^{* *}$ & $.39^{* *}$ \\
\hline R2 Image & .42 & .51 & .39 \\
\hline R2 WTB & .32 & .36 & .18 \\
\hline
\end{tabular}


Table 3: Construct measures in the CIP model

\begin{tabular}{|c|c|c|c|}
\hline Construct/Items & Factor Loadings & $\mathbf{C R}$ & AVE \\
\hline Animosity (Harmeling et al. 2015) & & .94 & .72 \\
\hline Contending emotions & .99 & 0.98 & .94 \\
\hline 1. Angry & .97 & & \\
\hline 2. Mad & .97 & & \\
\hline 3. Irritated & .92 & & \\
\hline Accommodating emotions & .69 & .96 & .88 \\
\hline 1. Worried & .80 & & \\
\hline 2. Afraid & .98 & & \\
\hline 3. Scared & .95 & & \\
\hline Affinity (adapted Thomson et al. 2005) & & .95 & .87 \\
\hline Admiration & .90 (second-order loadings) & .94 & .84 \\
\hline 1. Captivated & .82 & & \\
\hline 2. Impressed & .89 & & \\
\hline 3. Admire & .92 & & \\
\hline Liking & .98 & .92 & .79 \\
\hline 1. Like & .89 & & \\
\hline 2. Fondness & .90 & & \\
\hline 3. Sympathy & .70 & & \\
\hline Attachment & .79 & .98 & .94 \\
\hline 1. Connected & .94 & & \\
\hline
\end{tabular}




\begin{tabular}{|c|c|c|c|}
\hline 2. Bonded & .98 & & \\
\hline 3. Attached & .96 & & \\
\hline Country Image (adapted from Bagozzi et al. 2016) & & .97 & .90 \\
\hline 1. bad/good & .91 & & \\
\hline 2. unfavorable/favorable & .94 & & \\
\hline 3. negative/positive & .92 & & \\
\hline Willingness to buy (adapted from Oberecker and Diamantopoulos 2011) & & .96 & .90 \\
\hline 1. I intend to buy [country] [product category] in the future. & .94 & & \\
\hline 2. It is likely that I would choose [country] [product category]. & .94 & & \\
\hline 3. I consider buying [country] [product category]. & .89 & & \\
\hline Resistance to positive information (adapted from Eisingerich et al. 2011) & & .93 & .87 \\
\hline 1. I am skeptical toward positive things I hear about [country] [product category]. & .89 & & \\
\hline 2. If I heard positive news about [country] [product category], I would not believe them. & .84 & & \\
\hline Perceived attitudinal ambivalence (adapted from Wang et al. 2016) & & .94 & .84 \\
\hline When forming the reactions toward [country] [product category], you ... & & & \\
\hline 1....feel no conflict at all/feel very conflicted & .82 & & \\
\hline $2 . .$. feel no indecision at all/ feel very indecisive. & .85 & & \\
\hline 3. ...feel not at all mixed / feel very mixed & .94 & & \\
\hline
\end{tabular}




\section{FIGURES}

Figure 1: Schematic outline of the CIP model

\section{Country-induced predispositions (CIP)}

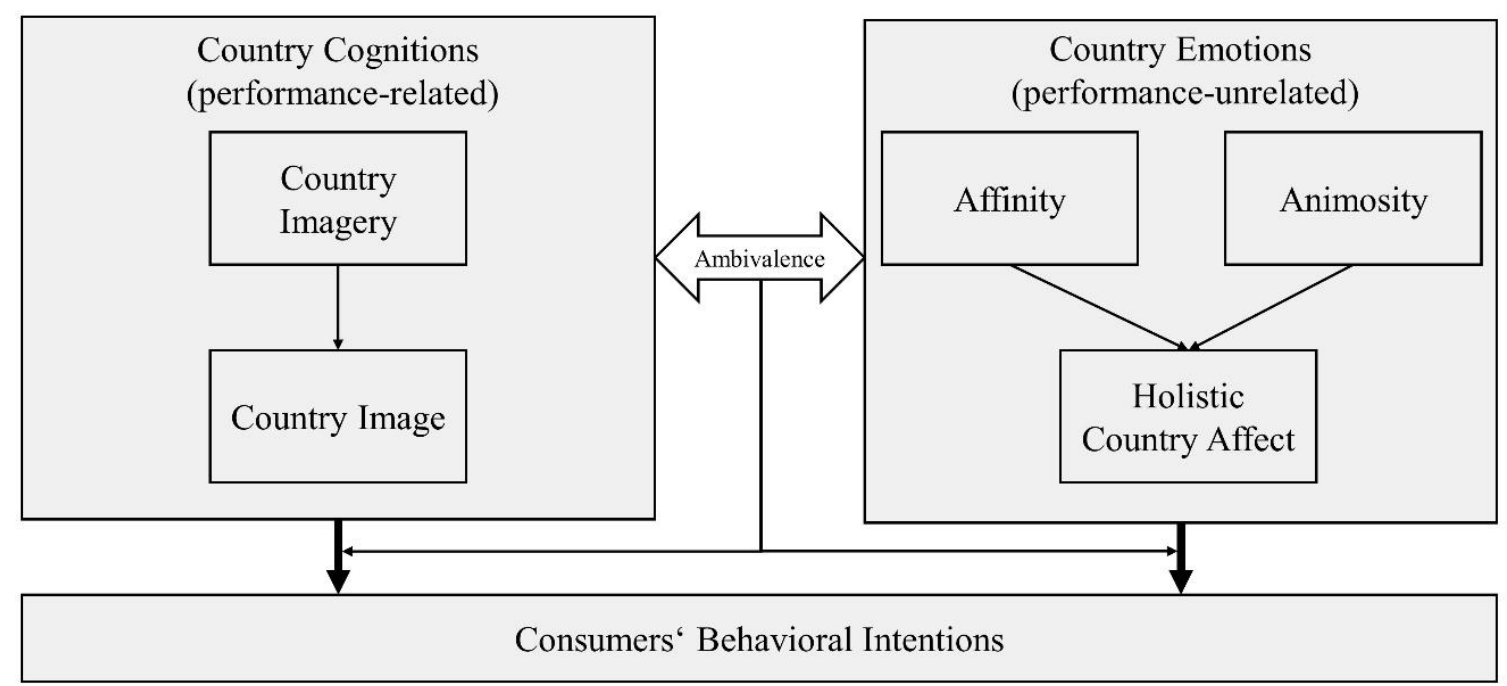

Figure 2: Measurement process of country imagery

\section{Qualitative Pre-Study}

Purpose: Unrestricted association set elicitation

\section{Quantitative Study}

Purpose: Measuring an individual imagery index
1. Semi-structured interviews

- Open-ended questions, asking consumers to formulate their own associations with a specific country in a specific product category.

- Probing to elicit specific associations, rather than generic ones (e.g. good cars).

\section{Defining the association set}

- Clustering of synonymous expressions under the label that is a) best representative of the underlying meaning, and b) most frequently mentioned.

- Calculation of weighted averages for every association based on a) frequency and b) order of mention. Establishing a threshold of $50-70 \%$ for the weighted averages.

\section{Capturing association strength and association valence}

- Closed-ended questionnaire, asking consumers to report association strength ('How much do you relate this attribute to [country]?') and valence (,For you as a consumer considering buying [product category] from [country], would this attribute be rather negative or positive?') for every association.

2. Calculating the imagery index

- Forming the algebraic composite for every individual i: Imageryi $=\sum$ Strengthi $x$ Valencei

- Ensuring correct construct specification through confirmatory tetrad analysis and low VIF's (i.e. $<3.3$ ). 
Figure 3: Empirical results of the CIP model

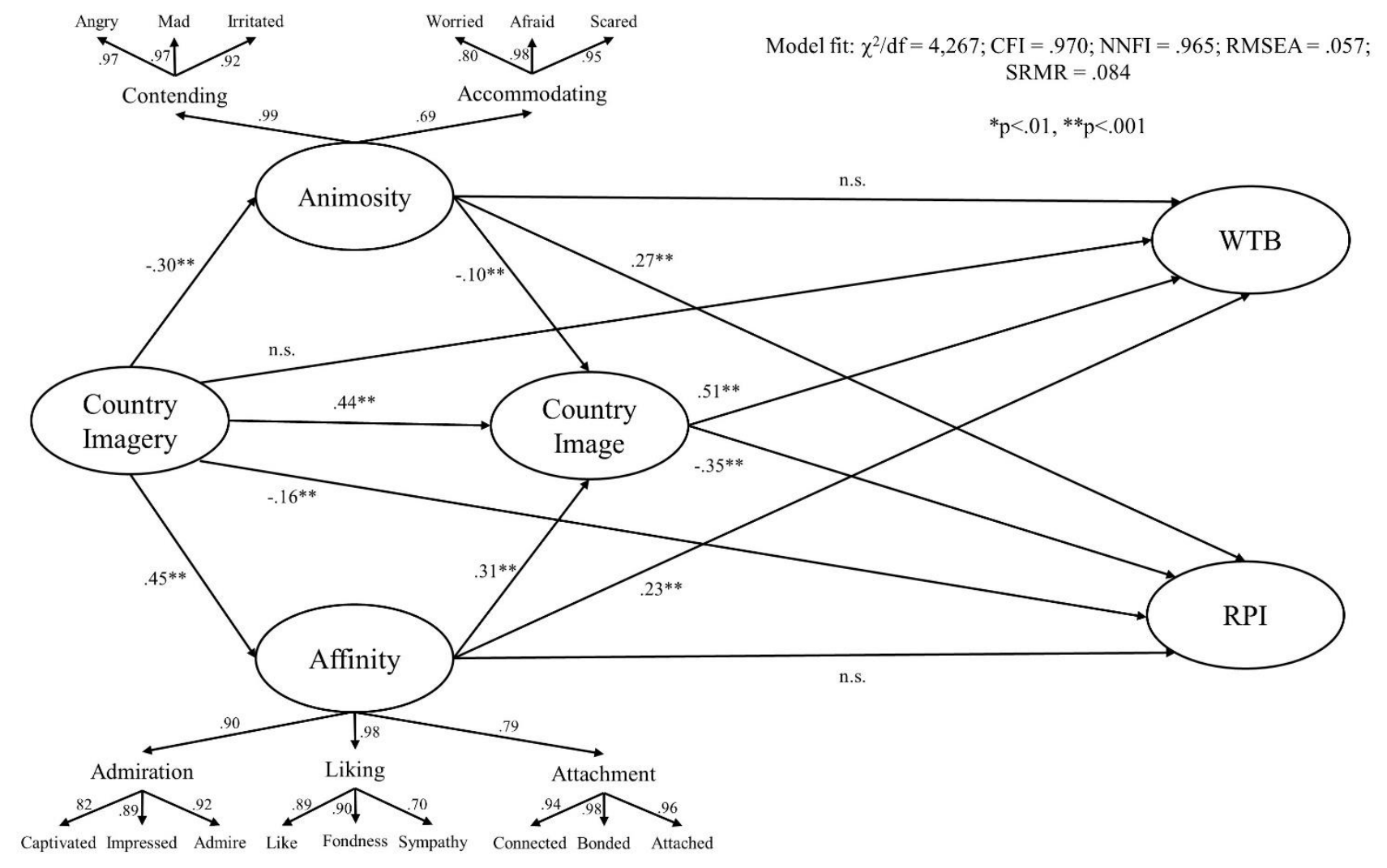

Figure 4: The CIP Measurement Matrix - A guiding tool for researchers and managers depending on the aim of the research

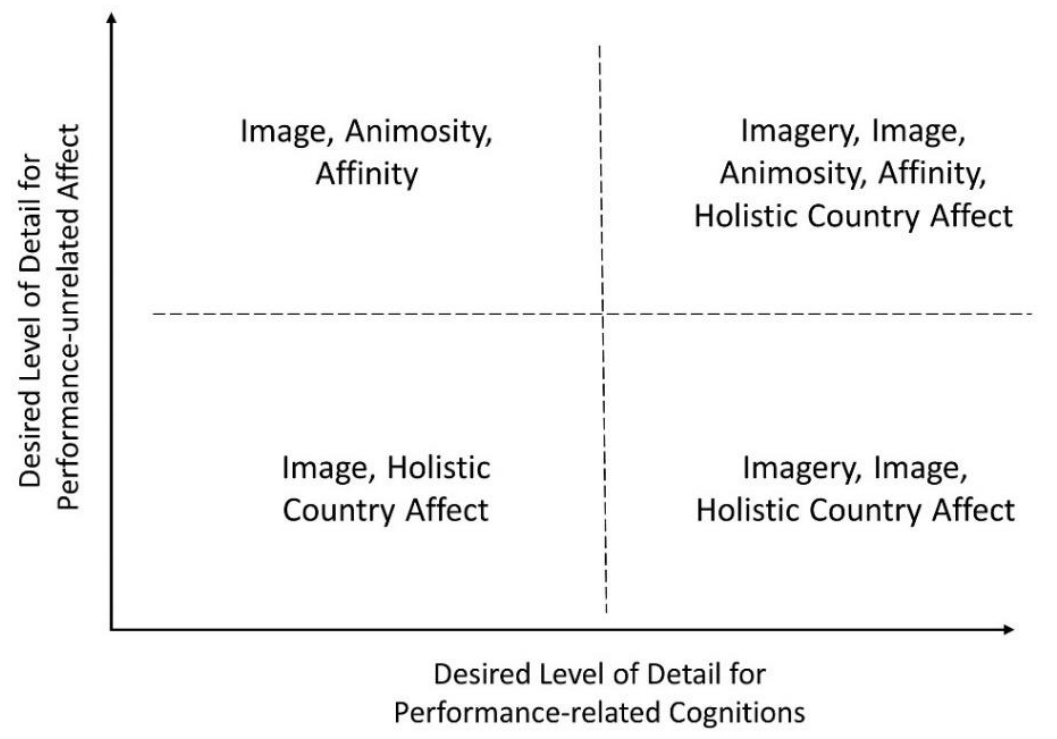

